\title{
PELUANG PASAR EKSPOR TUNA INDONESIA : SUATU PENDEKATAN ANALISIS BAYESIAN
}

\section{Opportunities of Tuna Indonesia Export Market: A Bayesian Analysis Approach}

\author{
*Risna Yusuf, Freshty Yulia Arthatiani dan Hertria Maharani Putri \\ Balai Besar Riset Sosial Ekonomi Kelautan dan Perikanan \\ Gedung Balitbang KP I Lt. 4 \\ Jalan Pasir Putih Nomor 1 Ancol Timur, Jakarta Utara, Indonesia \\ Telp: (021) 64711583 Fax: 64700924 \\ Diterima tanggal:15 Maret 2017 Diterima setelah perbaikan: 5 Mei 2017 \\ Disetujui terbit: 6 Juni 2017 \\ "email: risna.sujana@yahoo.com
}

\begin{abstract}
ABSTRAK
Tujuan penelitian ini mengetahui peluang pasar tuna di pasar tujuan ekspor utama Indonesia. Penelitian berlangsung pada bulan Maret - Juli 2014 dengan metode pengumpulan data berupa studi literatur, survey dan wawancara ke informan kunci. Pengumpulan data terdiri dari data primer dan sekunder. Analisis data dilakukan menggunakan pendekatan Bayesian. Hasil penelitian menunjukkan bahwa pasar tuna Indonesia dominan ke pasar Jepang sebesar 54\%, diikuti pasar USA sebesar $24 \%$ dan pasar UE sebesar $23 \%$. Selanjutnya komoditas dominan yang diperdagangkan adalah tuna kaleng dengan probabilitas sebesar $54 \%$, yang diikuti tuna segar sebesar $26 \%$ dan tuna beku sebesar $24 \%$. Untuk daerah ekspor, lokasi ekspor dengan probabilitas tertinggi berasal dari Jakarta yaitu sebesar $49 \%$, diikuti Surabaya sebesar 36\% dan Bitung sebesar 15\%. Lokasi ekspor tersebut mendapat pasokan dari berbagai daerah. Ketiga lokasi ekspor berasal dari enam daerah dengan probabilitas Jakarta (14\%), Sukabumi (21\%), Jawa Timur (4\%), Bitung (19\%), Maluku (14\%) dan Bali (26\%). Pada level ini armada penangkapan yang dominan digunakan untuk ekspor tuna terdiri dari armada motor tempel (22\%), dengan menggunakan jenis alat tangkap tuna handline $(31 \%)$ sebagai alat tangkap yang dominan. Oleh karena itu, untuk menjaga dan mempertahankan konsistensi ekspor tuna Indonesia, diperlukan suatu strategi pemasaran yang tepat yaitu strategi penetrasi pasar dimana pada strategi ini diperlukan berbagai upaya yang tepat agar market share perikanan tuna Indonesia terus meningkat. Salah satu upaya tersebut adalah dengan melakukan aspek penelusuran bahan baku tuna dengan memperhatikan daerah baik daerah yang mengekspor maupun daerah asal ikan tersebut ditangkap dan jumlah armada serta alat tangkap yang digunakan dalam proses penangkapan tuna Indonesia disamping upaya-upaya lain dari sisi hulu sampai hilir.
\end{abstract}

Kata Kunci: peluang pasar, ekspor, tuna, model bayesian

\section{ABSTRACT}

The purpose of this research is to know the tuna market opportunity in Indonesia's main export destination market. The research took place in March - July 2014 with data collection method in the form of literature study, survey and interview to key informant. The data collection consists of primary and secondary data. Data analysis was performed using Bayesian approach. The results show that Indonesia's tuna market is dominant to the Japanese market by $54 \%$, followed by USA market $24 \%$ and EU market by $23 \%$. Furthermore, the dominant commodities traded were canned tuna with probability of $54 \%$, followed by fresh tuna of $26 \%$ and frozen tuna of $24 \%$. For export areas, the highest probability export location came from Jakarta with $49 \%$, followed by Surabaya with $36 \%$ and Bitung at $15 \%$. The export location is supplied from various regions. The three export locations are from six regions with the probability of Jakarta (14\%), Sukabumi (21\%), East Java (4\%), Bitung (19\%), Maluku (14\%) and Bali (26\%). At this level the dominant fishing fleet used for tuna exports consists of an outboard motor fleet (22\%), using a handcraft tuna catch type (31\%) as the dominant fishing gear. Therefore, to maintain and maintain the consistency of Indonesian tuna exports, an appropriate marketing strategy is needed, which is a market penetration strategy in which this strategy is required to make appropriate efforts to increase the market share of tuna fisheries in Indonesia. One such effort is to conduct trace aspects of tuna raw material by taking into account the areas of both the exporting area and the origin of the fish were captured and the number of fleets and fishing gear used in the Indonesian tuna catching process in addition to other efforts from upstream to downstream.

Keywords: market opportunity, export, tuna, bayesian model 


\section{PENDAHULUAN}

Industrialisasi Kelautan dan Perikanan merupakan suatu konsep yang diusung oleh Kementerian Kelautan dan Perikanan dalam mendorong percepatan pembangunan ekonomi nasional khususnya pembangunan Kelautan dan Perikanan. Kebijakan ini menitikberatkan sistem produksi dari hulu ke hilir untuk meningkatkan nilai tambah, produktivitas, dan skala produksi sumberdaya kelautan dan perikanan (Sunoto, 2010).

Komoditas tuna merupakan salah satu komoditas unggulan dalam program industrialisasi. Hal ini dikarenakan tuna merupakan jenis ikan ekonomis tinggi dan merupakan komoditas penghasil devisa negara nomor dua untuk komoditas perikanan setelah udang. Pada tahun 2011, komoditas tuna, menyumbang nilai ekspor sebesar US\$ 498.591 .000 atau $14 \%$ dari total nilai ekspor perikanan Indonesia. Pada tahun 2009, secara angka potensi produksi komoditas tuna di Indonesia diperkirakan hampir mencapai 1,2 juta ton per tahun, dengan nilai ekspor lebih dari 3,5 miliar Dolar Amerika Serikat (AS).

Jika dilihat dari hasil produksi, pada tahun 2011 produksi tuna dunia sebesar 6,8 juta ton dan pada tahun 2012 meningkat menjadi lebih dari 7 juta ton. Dari produksi tersebut Indonesia memasok lebih dari 16\% produksi tuna dunia. Selanjutnya pada tahun 2013, volume ekspor tuna mencapai sekitar 209.410 ton dengan nilai USD \$ 764,8 juta (Direktorat Jenderal Pengolahan dan Pemasaran Hasil Perikanan (Ditjen P2HP), 2014). Tuna juga diketahui memiliki permintaan konsumen yang cukup tinggi akibat mulai bergesernya selera konsumen dunia dari red meat ke white meat. Dengan potensi yang dimiliki dan peluang pasar yang besar, sehingga tidak mengherankan apabila sebagian besar produksi tuna Indonesia di ekspor ke beberapa negara tujuan seperti Jepang, Uni Eropa dan Amerika. Permintaan tuna di Jepang dan Amerika Serikat dari tahun ke tahun selalu mengalami peningkatan. Pasar Jepang lebih memilih tuna fresh karena cocok untuk digunakan sebagai bahan baku pembuatan sashimi yang digemari oleh konsumen Jepang dan dapat langsung dikonsumsi. Sementara itu, konsumen tuna di Amerika Serikat lebih suka makan sandwich sehingga pasar tuna Amerika lebih banyak mengimpor tuna frozen (Lestari, 2012).
Peluang pasar perikanan tuna Indonesia di pasar ekspor tersebut (sisi hilir) tentunya tidak terlepas dari ketersediaan bahan baku komoditas tuna yang ada di perairan laut Indonesia (sisi hulu) . baik dari sisi kuantitas maupun kualitas bahan baku komoditas tuna sehingga dapat memberikan kontribusi positif terhadap market share komoditas tuna Indonesia di pasar ekspor. Market share komoditas ini diukur dengan melihat seberapa besar peluang perikanan tuna Indonesia di pasar ekspor tersebut sehingga dapat meningkatkan kinerja perikanan tuna Indonesia. Oleh karena itu perlu adanya jaminan agar ekspor komoditas tuna tersebut tetap konsisten dan mengalami peningkatan, Dalam menjaga dan mempertahankan konsistensi ekspor perikanan tuna Indonesia dan meningkatkan market share nya pada Negara tujuan, diperlukan aspek ketelusuran bahan baku komoditas tuna yang diekspor yang meliputi aspek pasar ekspor, komoditas, daerah ekspor, daerah asal, jenis armada penangkapan dan jenis alat tangkap. Ketertelusuran merupakan kemampuan suatu sistem untuk mengenali dan menelusuri suatu produk dari hulu sampai hilir yaitu mulai pada setiap tahapan produksi, pengolahan maupun pemasaran. Tujuannya adalah untuk mencatat/ mendokumentasikan produk mulai dari bahan baku sampai kepada konsumen (from farm to fork). Pada prakteknya, implementasi sistem ketertelusuran pada produk perikanan di Indonesia masih terbatas pada produk hasil industri maupun produk ekspor (Dwiyitno, 2009).

Tujuan penelitian ini mengetahui seberapa besar peluang pasar perikanan tuna di negara yang menjadi pasar tujuan ekspor tuna Indonesia. Diharapkan dengan penelitian ini dapat memberikan masukan kepada pemerintah sehingga diperoleh langkah-langkah yang tepat dalam upaya untuk meningkatkan ekspor perikanan tuna Indonesia.

\section{METODOLOG}

Penelitian ini dilaksanakan mulai bulan Maret sampai dengan Juli 2014. Lokasi yang menjadi fokus penelitian ini adalah Jakarta, Sulawesi Utara (Bitung), Jawa Timur (Surabaya), dan Ambon. Pemilihan lokasi Jakarta, Surabaya dan Bitung sebagai lokasi untuk menganalisis strategi penetrasi pasar ekspor didasarkan pada pertimbangan bahwa pada ketiga lokasi tersebut merupakan daerah terbesar dalam mengekspor Tuna Indonesia ke negara tujuan utama. Lokasi lainnya merupakan daerah asal produksi tuna terbesar di Indonesia. 


\section{Data dan Sumber Data}

Data yang digunakan dalam penelitian ini adalah data primer dan data sekunder.Data primer yang diperoleh adalah data yang terkait dengan aspek-aspek sosial ekonomi dalam perikanan tuna yang mempengaruhi setiap tahapan hirarki diperoleh dengan menggunakan kuesioner terstuktur kepada pelaku usaha perikanan selaku responden dalam penelitian ini. Data sekunder diperoleh dari instansi terkait seperti Dinas Kelautan dan Perikanan, Pelabuhan Perikanan, Badan Pusat Statistik (BPS), Badan Pengujian Mutu dan Hasil Perikanan, Dinas Perindustrian dan Perdagangan serta pusat data dan informasi Kementerian Kelautan dan Perikanan.

\section{Metode Analisis}

Data yang diperoleh dalam penelitian ini selanjutnya dianalisis dengan menggunakan analisis deskriptif untuk melihat kondisi eksisting ekspor perikanan tuna Indonesia di pasar tujuan utama (Jepang, USA dan UE) dan analisis forensik pemasaran dengan pendekatan Bayesian dimana pendekatan Bayesian merupakan salah satu teknik yang banyak digunakan untuk membedah berbagai permasalahan yang didasarkan pada kemungkinan-kemungkinan yang terjadi didalam suatu kasus (Jeynes, 1995). Metode ini banyak diaplikasikan untuk berbagai kepentingan karena dapat menghasilkan informasi yang baik dan hasil yang relatif cepat. Teori ini juga merupakan salah satu teori yang dapat digunakan untuk melakukan estimasi selain pendekatan statistik klasik. Statistik klasik menitikberatkan pada proses inferensia yang diambil dari data sampel pada suatu populasi sedangkan pada statistik yang mengadopsi bayes atau lebih sering disebut dengan statistik Bayesian selain memanfaatkan data sampel dari suatu populasi juga memperhitungkan distribusi awal yang disebut prior (Preatin et al., 2007). Distribusi posterior kemudian dapat ditentukan dari distribusi prior sehingga diperoleh penduga atau estimator Bayesian yang berupa mean atau modus dari distribusi posterior. Pendekatan tersebut untuk melihat peluang peningkatan market share dalam mendukung ekspor perikanan tuna Indonesia (Gambar 1).

Peluang suatu kejadian yang sudah terjadi, atau peluang awal (prior probability) pada berbagai kondisi atau situasi, $\varnothing_{\mathrm{i}}$, didefinisikan dengan $P\left(\varnothing_{\mathrm{i}}\right)$. Informasi tambahan yang diperoleh melalui investigasi atau penyelidikan yang disebut dengan $\mathrm{e}_{\mathrm{k}}$ jika $\varnothing_{\mathrm{j}}$ telah terjadi. Peluang kondisionalnya (conditional probability) dapat dinotasikan dengan $\mathrm{P}\left(\mathrm{e}_{\mathrm{k}} / \varnothing_{\mathrm{j}}\right)$. Dalam hal ini, $\varnothing_{\mathrm{j}}$ disebut dengan kejadian awal (state of nature), $\mathrm{j}=1,2, . . \mathrm{n}$, atau terdapat $\mathrm{n}$ kejadian awal.

Bila informasi $e_{k}$ dijadikan sebagai kondisi untuk menghitung kembali peluang kejadian $\varnothing_{\mathrm{i}}$, maka pendekatan Bayesian dapat digunakan untuk menentukan peluang posterior (posterior

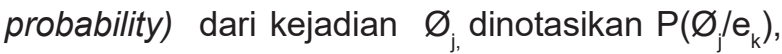
yang diformulakan sebagai berikut:

$$
\begin{aligned}
& P\left(\varnothing_{j} / e_{k}\right)=\left\{\left(P\left(\varnothing_{j}\right) \cdot P\left(e_{k} / \varnothing_{j}\right)\right\} / P\left(\varnothing_{j}\right) \cdot P\left(e_{k} / \varnothing_{j}\right) ;\right. \\
& j=1,2, \ldots n\} .
\end{aligned}
$$

Secara skematis, proses Bayesian ini dapat ditampilkan seperti pada Gambar 1. Berdasarkan Gambar 1, dapat diterangkan bahwa proses Bayesian adalah transisi antara peluang awal (prior probability) dan peluang akhir (posterior). Keputusan manajemen atau ekonomi memang diambil berdasarkan peluang awal. Namun demikian karena ada informasi baru maka, pengambil keputusan (decision-maker) sepatutnya

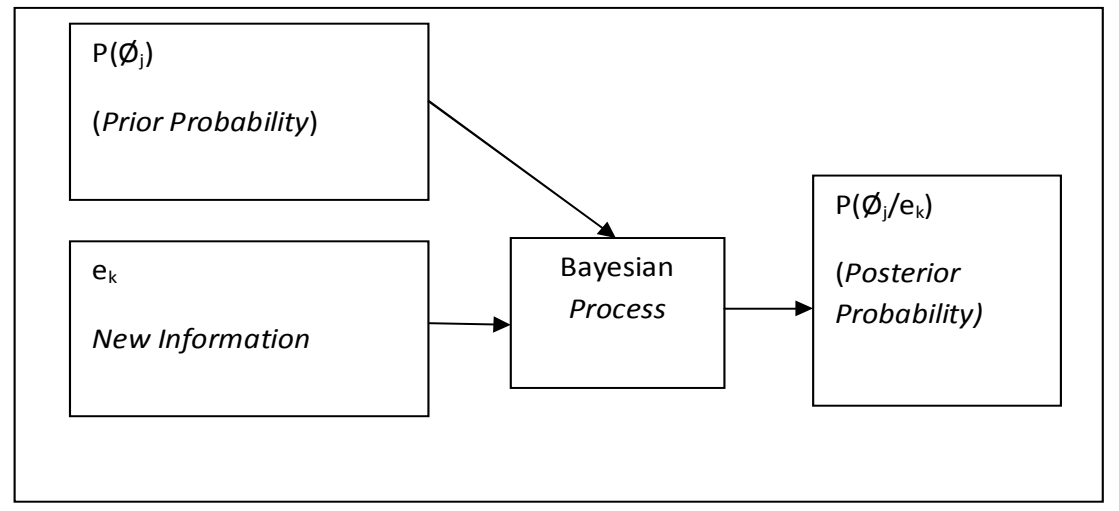

Gambar 1. Skema Proses Bayesian (Nikijuluw, 2014)

Figure 1. The Bayesian Process Scheme (Nikijuluw, 2014) 
menggunakan informasi baru tersebut untuk pengambilan keputusannya sehingga makin akurat. Proses penambahan informasi baru yang diolah dengan pendekatan Bayesian akan menghasilkan keputusan yang lebih baik, yang berdasarkan atas posterior probability. hasil yang tepat sampel, integrasi pengambilan keputusan, 'estimasi', 'percobaan', dan pemilihan model. Teorema Bayes menurut Syamsudin (2011) memungkinkan dua buah sumber informasi tentang parameter dari suatu model statistic digabung menjadi satu. Dengan teorema ini informasi sampel

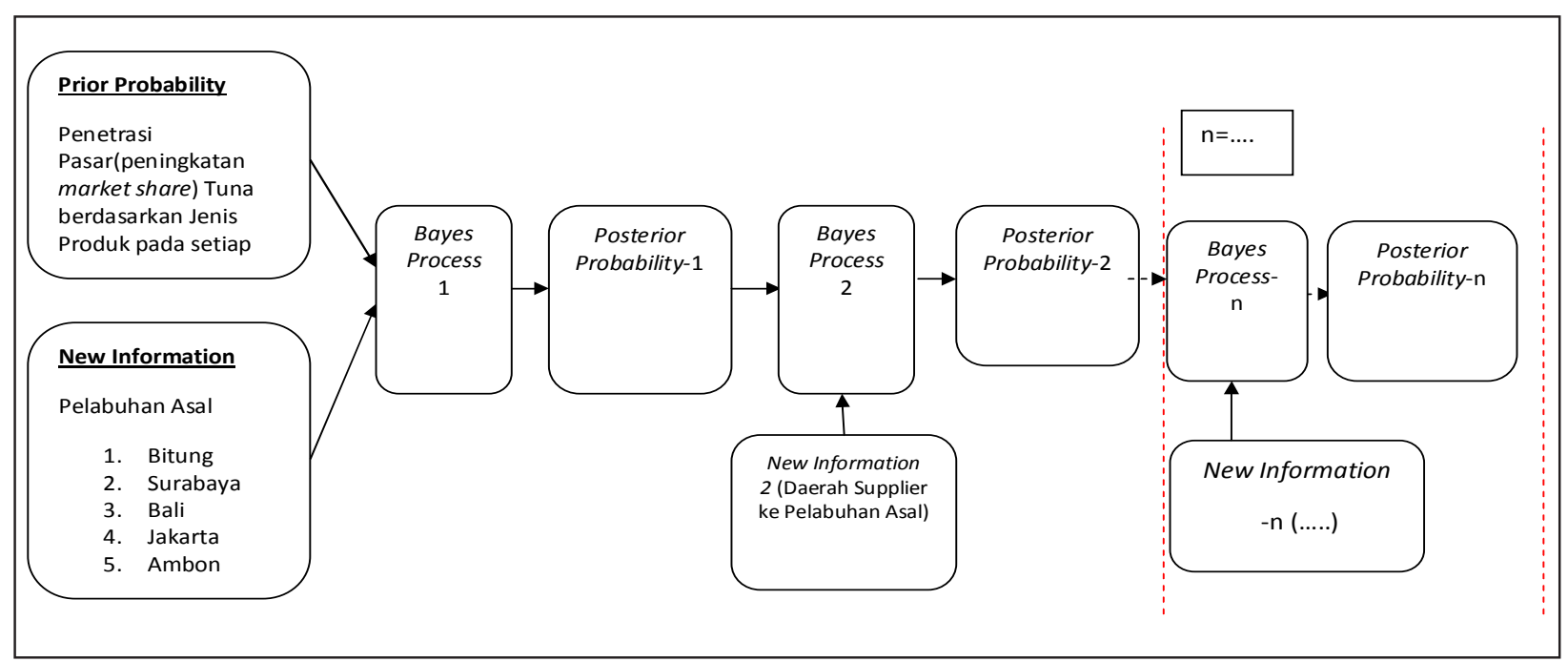

Gambar 2. Alur Analisis Forensik Perikanan Tuna dengan Menggunakan Pendekatan Analisis Bayesian.

Figure 2. Tuna Fisheries Forensic Analysis Flow Using The Bayesian Analysis Approach.

Pendekatan Bayesian menurut Rossi (2002), menjelaskan bagaimana model hirarkis Bayes ideal untuk diterapkan pada pengambilan keputusan di bidang pemasaran berdasarkan data yang diperoleh. Pendekatan ini fokus pada membuat pernyataan probabilitas mengenai parameter dan jumlah diperkirakan tergantung pada sampel. Pendapat lain terkait pendekatan Bayesian yang dikemukakan oleh Liu and Shang (2012) dimana banyak faktor ketidakpastian yang ada di lingkungan pasar, sehingga memiliki tingkat resiko pada proses pengambilan keputusan. Solusi informasi yang tepat dapat meningkatkan reabilitas pengambilan keputusan. dengan melalui informasi umum, resiko yang didasarkan pada pengambilan keputusan, maka dengan penggunaan bayesian, priori analysis dan posterior analysis, informasi yang diberikan dapat menentukan nilai dan meningkatkan keandalan resiko pengambilan keputusan dengan cara yang efektif. Sebuah analisis Bayesian menggabungkan sebelumnya dan kemungkinan untuk menghasilkan distribusi posterior untuk semua teramati jumlah yang mencakup parameter dan prediksi. Pandangan tradisional menyebutkan bahwa inferensi Bayesian memberikan manfaat (fungsi likelihood) dan informasi prior (distribusi prior) bisa digabung menjadi informasi posterior.

Penyusunan model Bayesian tersebut diharapkan dapat menggambarkan sebuah model statistic yang berasal dari berbagai informasi dan data faktual pada setiap aspek -aspek dalam perikanan Tuna Indonesia yang bertujuan untuk mendapatkan informasi dari hulu hingga hilir perikanan Tuna di Indonesia baik dalam pasar ekspor. Informasi posterior tersebut selanjutnya dikaji untuk menghasilkan sebuah rekomendasi kebijakan terkait dengan peluang pasar tuna Indonesia dalam meningkatkan pangsa pasar (market share) di berbagai pasar yang dimaksud. Dalam meningkatkan pangsa pasar (market share) perikanan tuna Indonesia di pasar utama tentunya dipengaruhi oleh berbagai aspek yang terdiri dari 7 (tujuh) hirarki meliputi pasar tujuan ekspor utama perikanan tuna, komoditas ekspor, daerah ekspor, daerah asal komoditas tuna, jenis armada penangkapan dan jenis alat tangkap. Dengan melalui pendekatan analisis bayesian tersebut membutuhkan data lapang yang terkait dengan pasar ekspor Tuna Indonesia yang terdiri dari 7 hierarki yaitu: 
1. Pasar tujuan ekspor utama perikanan Tuna

Data statistik menunjukkan bahwa terdapat tiga pasar ekspor utama tuna Indonesia yaitu Jepang, USA dan Uni Eropa.

\section{Komoditas ekspor tuna pada pasar utama}

Komoditas tuna ekspor yang dihasilkan oleh Indonesia dibagi menjadi tiga kategori yaitu Fresh, Frozen dan Canned.

\section{Daerah Ekspor}

Daerah Ekspor merupakan daerah utama asal ekspor tuna ke negara tujuan utama, yang dapat diketahui tiga daerah utama adalah Jakarta melalui Pelabuhan Tanjung Priok dan Bandara Soekarno Hatta, Surabaya melalui Pelabuhan Tanjung Perak dan Bandara Djuanda, dan Bitung melalui Pelabuhan Bitung dan Bandara Sam Ratulangi

\section{Daerah Asal Komoditas Tuna}

Daerah asal komoditas tuna yang menjadi komoditas ekspor berasal dari enam daerah utama yaitu Jakarta, Sukabumi, Bali, Bitung, Maluku dan Jawa Timur.

\section{Jenis Armada Penangkapan}

Armada penangkapan dibagi berdasarkan kategori ukuran Gross Ton kapal. Hierarki yang kelima dari Bayesian model yang digunakan pada analisis forensik perikanan tuna Indonesia pada pasar ekspor adalah jenis armada penangkapan yang digunakan pada masing-masing daerah asal komoditas yang merupakan posterior probability dari hierarki diatasnya. Armada penangkapan tersebut diklasifikasikan menjadi lima kategori motor temple, armada $\leq 10 \mathrm{G}$, armada 11-30 GT, armada 31-50 G, armada 51-100 GT dan Armada >100 GT.

\section{Jenis Alat Tangkap}

Jenis alat tangkap yang utama dalam produksi tuna adalah alat tangkap handline, purse seine, longline, pancing tonda, poll $\mathrm{n}$ line /huhate dan jaring insang. Di perairan Indonesia, yellowfin tuna dan bigeye tuna didapatkan didaerah pantai Selatan Jawa dan Barat Sumatera. Di perairan ini, terjadi percampuran antara perikanan tuna lapis dalam, yang dieksploitasi dengan alat rawai tuna, dengan perikanan tuna permukaan yang dieksploitasi menggunakan alat tangkap pukat cincin, gillnet, tonda dan payang. Karakteristikikan tuna yang telah disebutkan diatas menyebabkan terdapat berbagai alat penangkapan ikan yang digunakan di Indonesia.

Penelitian ini tidak hanya melihat ketujuh hirarki yang digunakan dalam pendekatan analisis Bayesian, tetapi juga melihat aspek sosial ekonomi yang mempengaruhi pada setiap hirarki tersebut.

\section{HASIL DAN PEMBAHASAN}

\section{Kondisi Eksisting Pasar Tuna Indonesia di Negara Tujuan Utama}

Pada pasar global, tuna merupakan komoditas perikanan yang memiliki nilai ekonomis tinggi. Tingginya permintaan atas komoditas ini menyebabkan komoditas tuna menjadi salah satu primadona dalam komoditas perikanan dengan harga jual yang cukup tinggi. Secara statistik, permintaan impor ikan tuna dunia adalah sebesar 1.101.646 ton pertahun, dan dari jumlah tersebut Indonesia baru dapat mensuplai 7,52\% dari kebutuhan dunia tersebut. Apabila dilihat dari volume produksi, jenis tuna yang paling mendominasi adalah skipjack tuna atau yang lebih dikenal sebagai ikan cakalang di Indonesia $(50 \%)$. Jenis tuna lainnya yang cukup besar dipasaran adalah tuna sirip kuning (yellow fin tuna) $(31.7 \%)$ dan albakor (10.8\%) (Miyake et al., 2010).Pasar tujuan ekspor bagi negara-negara penghasil tuna di dunia cukup tersebar namun terdapat tiga negara utama yaitu Jepang, Amerika Serikat dan Uni Eropa. Ketiga pasar negara tersebut juga telah menjadi daerah tujuan ekspor bagi Indonesia. Pasar ikan tuna terbesar di dunia saat ini adalah Jepang, Amerika Serikat dan Uni Eropa. Ekspor ikan tuna ke Jepang sebesar 27 persen, dan ke Amerika Serikat 17 persen sedangkan ke Uni Eropa juga cukup besar volume dan nilainya yaitu sebesar 12 persen (Food and Agriculture Organization (FAO), 2011). Di kawasan ASEAN, Indonesia menempati urutan kedua sebagai negara produsen ikan tuna setelah Thailand. Hal ini disebabkan perbedaan tingkat eksploitasi baik dari segi jumlah maupun teknologi penggunaan alat tangkap. Mengingat bahwa perairan Indonesia masih luas maka peluang untuk meningkatkan produksi masih besar dan itu berarti juga peluang untuk meningkatkan ekspor sebagai penambah devisa negara juga besar (Winanti, 2011). 


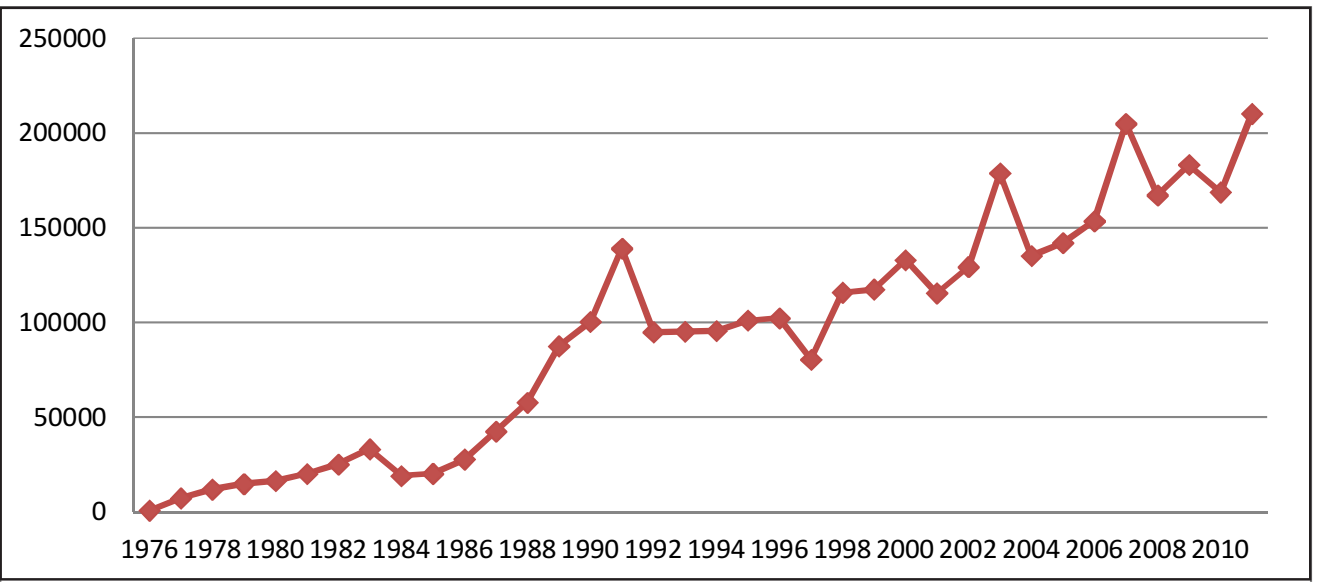

Gambar 3. Perkembangan Ekspor Tuna Indonesia Pada Tahun 1976-2010

Figure 3. The Development of Indonesia's Tuna Exports In 1976-2010

Sumber: FishStat Data (2011)/Source: FishStat Data (2011)

Berdasarkan data fishstat FAO diketahui bahwa ekspor tuna indoensia mengalami trend peningkatan yang cukup signifikan dari waktu ke waktu. Hal ini semakin menunjukkan bahwa produksi dalam negeri mengalami peningkatan dan semakin diterima pada tataran global. Ekspor tuna Indonesia menyumbang sekitar $4,3 \%$ terhadap total ekspor tuna dunia (Gambar 4).

Ekspor ikan tuna dibedakan berdasarkan negara tujuan ekspor, baik dalam bentuk segar (fresh), beku (frozen) dan kaleng (canned). Pengiriman dalam bentuk tersebut menyesuaikan dengan permintaan masing-masing negara tujuan. Untuk komoditas tuna segar, pada tahun 2012 Indonesia mengekspor sebesar 10.247.858 $\mathrm{kg}$ dengan nilai US\$71.021.675. Sedangkan untuk tuna beku, volume ekspornya jauh lebih besar yaitu $95.480 .689 \mathrm{~kg}$ dengan nilai US\$ 228.869.939. Sedangkan volume ekspor untuk tuna kaleng sebesar $72.184 .761 \mathrm{~kg}$ dengan nilai US\$ 351.534.881 (Tabel 1). Dari tabel tersebut juga telihat bahwa volume ekspor tuna segar pada tahun 2010-2012 mengalami penurunan sebesar $37 \%$, sedangkan untuk komoditas tuna beku dan tuna kaleng mengalami peningkatan dari tahun 2010-2012 masing-masing sebesar 49\% dan $28 \%$. Hal ini terkait dengan penelitian yang dilakukan oleh Lestari et al. (2013) dimana tuna olahan Indonesia mempunyai daya saing lebih tinggi bila dibandingkan dengan tuna beku, namun lebih rendah bila dibandingkan dengan tuna segar. Namun demikian, bila dibandingkan dengan negara pesaing, tuna olahan Indonesia mempunyai daya saing lebih rendah dan hanya mampu menduduki posisi ke-7. Faktor produksi dan pemasaran yang sangat berpengaruh terhadap daya saing ikan tuna olahan adalah: (1) Mutu ikan tuna olahan yang dihasilkan, (2) Hambatan tarif dan non tarif dan (3) Pengembangan market intellegence dan Promosi.

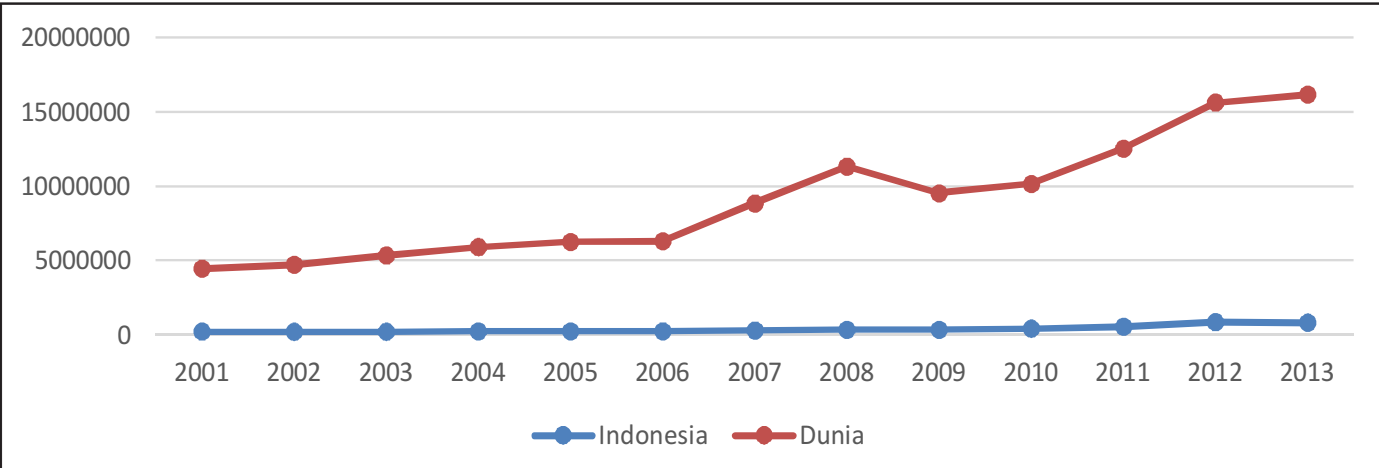

Gambar 4. Perkembangan Ekspor Tuna Indonesia Terhadap Ekspor Tuna Dunia PadaTahun 2001-2013. Figure 4. The Development of Indonesia's Tuna Export to Tuna Export in 2001-2013. 
Tabel 1. Perkembangan Volume Ekspor Tuna Indonesia Berdasarkan Jenis Komoditas Pada Tahun 2010-2012.

Table 1. The Development of Indonesian Tuna Export Volume by Type of Commodity in 2010-2012.

\begin{tabular}{ccccc}
\hline Jenis Komoditas/ & \multicolumn{3}{c}{ Volume/Volume (kg/tahun) } & \multirow{2}{*}{ \% /tahun/\%/year } \\
\cline { 2 - 4 } Commodity Type & $\mathbf{2 0 1 0}$ & $\mathbf{2 0 1 1}$ & $\mathbf{2 0 1 2}$ & \\
\hline $\begin{array}{c}\text { Tuna Segar/ } \\
\text { Fresh Tuna }\end{array}$ & 17.948 .974 & 13.378 .579 & 10.247 .858 & $-37 \%$ \\
$\quad$ Tuna Beku/ & 49.733 .516 & 58.452 .825 & 95.480 .689 & $49 \%$ \\
$\quad$ Frozen Tuna & & & \\
$\quad$ Tuna Kaleng/ & 54.767 .251 & 68.989 .252 & 72.184 .761 & $28 \%$ \\
$\quad$ Canned Tuna & & &
\end{tabular}

Sumber: Dirjen P2HP, KKP (2013)/Source:Directorate of Processing and Marketing Fishery Products (2013)

\section{Kondisi Eksisting Pasar Tuna Indonesia dengan Pendekatan Analisis Bayesian}

Kondisi pasar ekspor tuna Indonesia dengan menggunakan pendekatan analisis bayesian seperti pada Gambar 5 diperoleh hasil bahwa secara singkat dari ekspor tuna Indonesia yang memiliki tiga pasar utama yaitu Pasar Jepang, pasar USA dan pasar UE. Berdasaran kondisi tersebut diketahui probabilitas pada tiga pasar tersebut dimana pasar tuna Indonesia dominan ke pasar Jepang sebesar $54 \%$, diikuti pasar USA $24 \%$ dan pasar UE $23 \%$. Data tersebut diolah berdasarkan data factual nilai ekspor rata-rata komoditas tuna yang dikeluarkan oleh Ditjen P2HP, KKP.
Berdasarkan ketiga pasar tersebut, jenis komoditas yang dominan diperdagangkan adalah Canned Tuna dengan probabilitas sebesar $54 \%$, selanjutnya Fresh Tuna sebesar 26\% dan Frozen Tuna $24 \%$. Tahapan selanjutnya adalah daerah ekspor tuna Indonesia dimana daerah ekspor yang memiliki probabilitas tertinggi berasal dari Jakarta yaitu sebesar $49 \%$, diikuti Surabaya $36 \%$ dan Bitung 15\%. Selanjutnya, dilihat dari data statistik Dinas Kelautan dan Perikanan Propinsi Bali (2013) untuk daerah asal yang merupakan daerah utama tempat pendaratan ikan tuna terbanyak adalah Bali dengan tingkat probabilitas sebesar $26 \%$, Sukabumi sebesar $21 \%$, Bitung sebesar $19 \%$, Jakarta (14\%) dan Jawa Timur (4\%). Selanjutnya

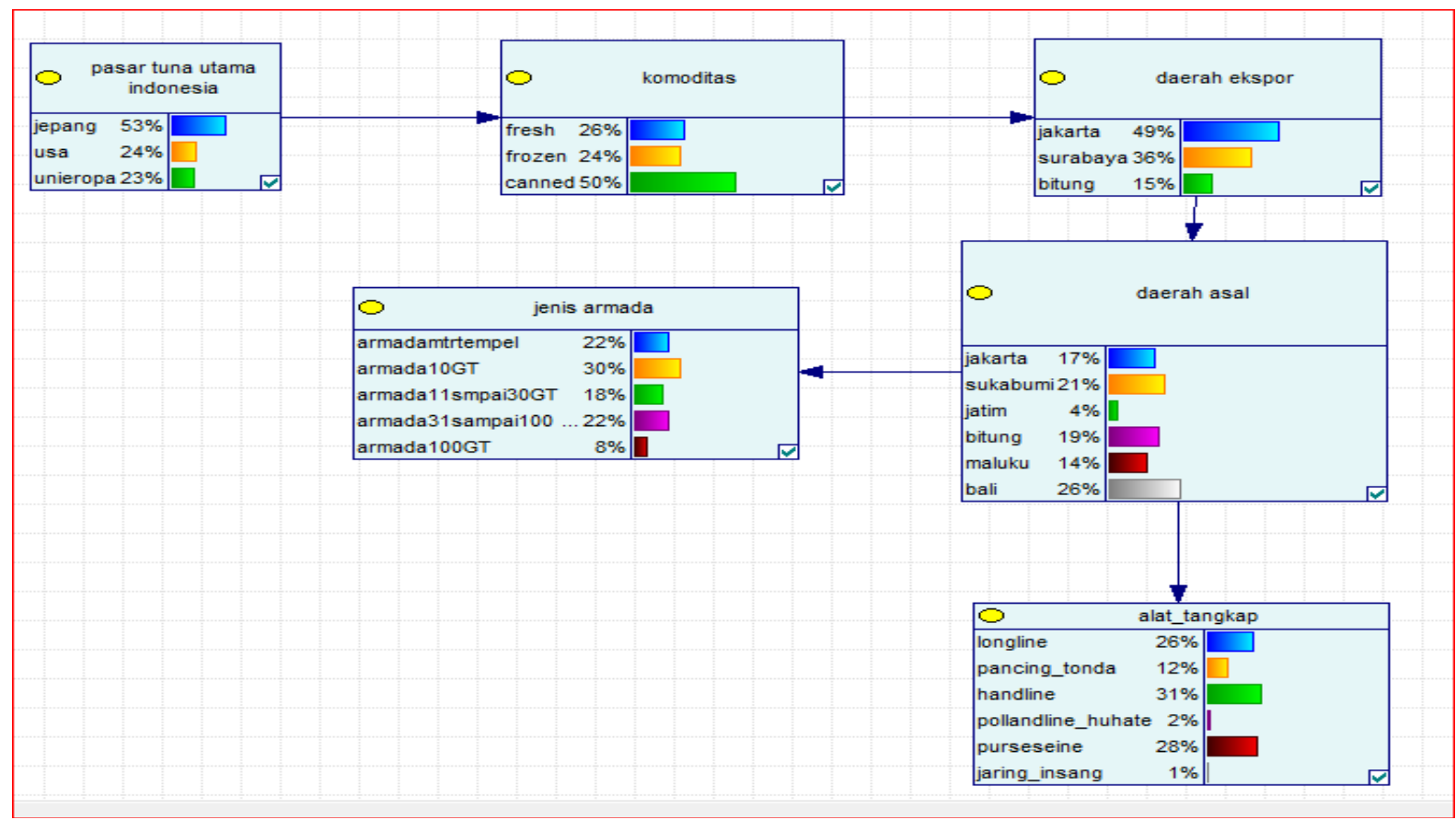

Gambar 5. Kondisi Pasar Ekspor Tuna Indonesia dengan Pendekatan Analisis Bayesian. Figure 5. Tuna Export Market Condition of Indonesia with Bayesian Analysis Approach. 
pada level armada penangkapan, dimana armada penangkapan dominan digunakan untuk tuna adalah armada $\leq 10$ GT $(30 \%)$, armada motor tempel (22\%), armada 31-100 GT (18\%), armada $11-30$ GT (12\%) dan armada $\geq 100$ GT (8\%).

Terakhir, pada jenis alat tangkap tuna yang digunakan, hasil analiis menunjukkan bahwa alat tangkap yang dominan adalah handline (31\% ). Purse seine (28\%), kemudian diikuti longline (26\%). Alat tangkap lainya yang juga menyumbang dalam produksi tuna antara lain adalah pancing tonda $(12 \%)$, pool $n$ line/ huhate $(2 \%)$ dan jaring insang (1\%). Data diatas menunjukkan bahwa alat tangkap pancing masih menjadi alat tangkap utama untuk komoditas tuna, hal ini disebabkan jenis alat tangkap ini dianggap dapat menjaga kualitas dari hasil tangkapan tuna yang dihasilkan. Namun kondisi terakhir juga menunjukkan bahwa alat tangkap purse seine yang merupakan alat tangkap jaring dengan selektifitas yang rendah terhadap jenis ikan juga memberikan kontribusi yang cukup besar bagi produksi tuna Indonesia sebesar $28 \%$.

\section{Simulasi Peluang Pasar Perikanan Tuna di Negara Tujuan Utama}

Berdasarkan kondisi perikanan tuna Indonesia yang sudah dijelaskan di atas, selanjutnya dilakukan simulasi ekspor perikanan tuna Indonesia pada ketiga Negara tujuan tersebut (Jepang, USA dan UE). Simulasi ini dilakukan dengan tujuan untuk melihat sejauhmana peluang yang diperoleh jika ekspor perikanan tuna Indonesia pada ketiga Negara tersebut ditingkatkan. Secara rinci, simulasi tersebut dapat dijelaskan seperti pada Gambar 6 dibawah ini.

Apabila dilakukan simulasi peluang pasar Jepang seperti pada gambar 6 di atas, dalam arti jika ingin meningkatkan market share perikanan tuna Indonesia di pasar Jepang, maka komoditas yang dominan adalah Fresh tuna dengan probabilitasnya sebesar $45 \%$ dimana daerah ekspor utama adalah Jakarta dengan probabilitas sebesar $62 \%$ dan daerah asal adalah Bali dengan probabilitas mencapai $25 \%$ dengan armada yang digunakan armada 10 GT sebesar $28 \%$ dan alat tangkap yang digunakan yaitu handline dengan probabilitas sebesar $33 \%$.

Berdasarkan hasil wawancara dengan pelaku usaha, ternyata aspek sosial ekonomi yang berpengaruh dalam penentuan ekspor tuna di pasar Jepang adalah preferensi konsumen di Jepang yaitu sebesar $20 \%$ dan permintaan tuna di Jepang yang tinggi yaitu sebesar $19 \%$. Konsumen Jepang memiliki tingkat konsumsi ikan yang tinggi, disamping itu mereka lebih menyukai ikan tuna dalam bentuk segar, biasanya ikan tuna dalam bentuk segar langsung diekspor melalui jalur udara. Biasaya tuna segar diekspor dalam bentuk whole fresh tuna. Penelitian ini memperkuat kajian lain yang tekait dengan produk tuna Indonesia di pasar

\section{Pasar Jepang}

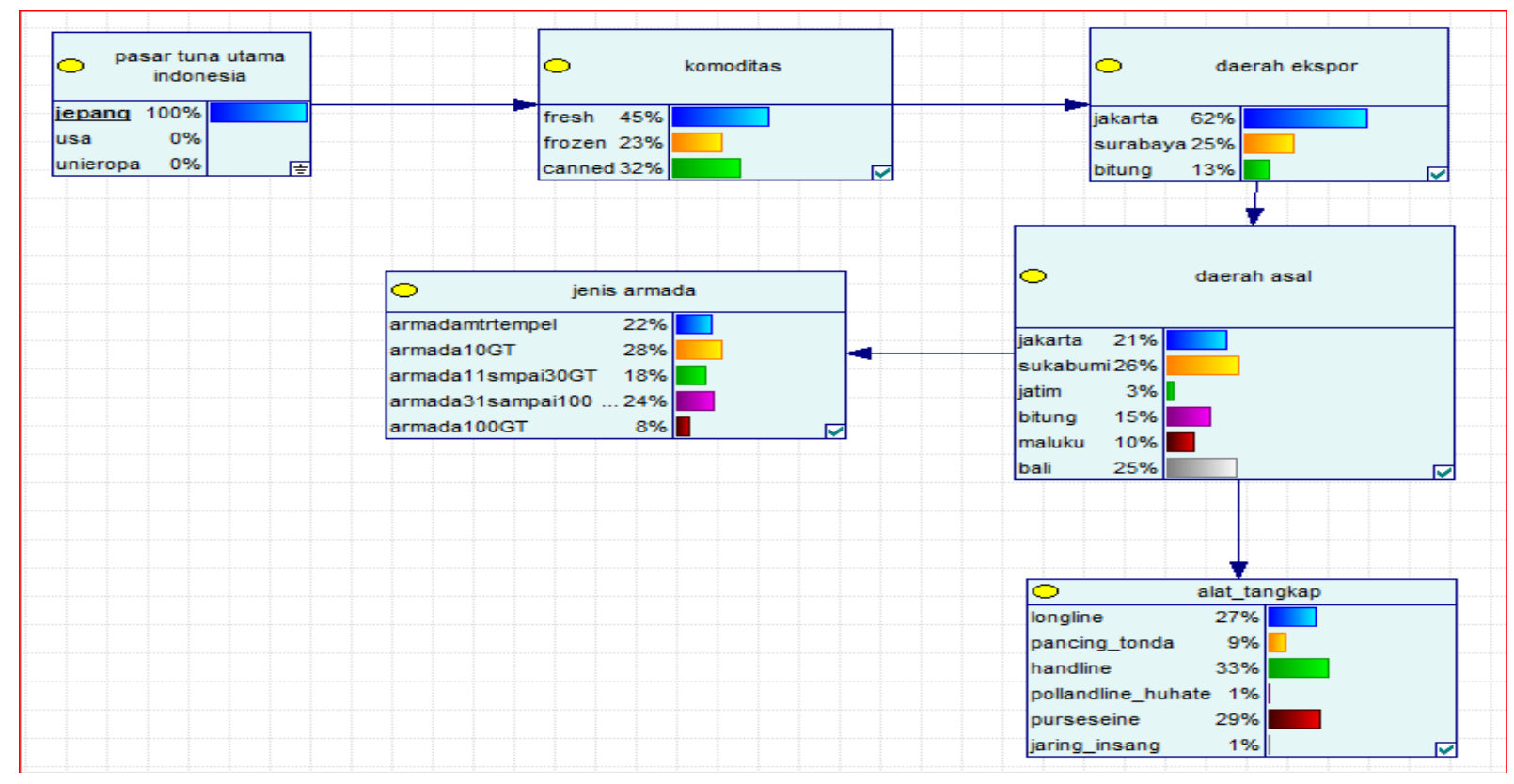

Gambar 6. Data Hasil Olahan Pasar Jepang(2014). Figure 6. Processed Data for Japan (2014). 
Jepang, dimana permintaan impor tuna Indonesia oleh pasar Jepang peka terhadap perubahan pendapatan nasional Jepang, tingkat konsumsi ikan dan produksi tuna domestik Jepang, sedangkan volume impor tuna Indonesia oleh pasar Jepang dipengaruhi secara nyata oleh faktor indikator ekonomi Jepang. Dengan hasil penelitian tersebut diperkirakan bahwa volume permintaan impor tuna Indonesia oleh pasar Jepang pada 10 tahun yang akan datang akan mengalami peningkatan sebesar $45,36 \%$ atau $59.653,41$ ton. Oleh karena itu yang dapat dilakukan adalah memelihara preferensi konsumen Jepang terhadap tuna Indonesia karena adanya jaminan bahwa pasar Jepang masih prospektif dan eksportir tidak perlu takut dalam meningkatkan harga riil tuna Indonesia (Koestranti, 1993).

Apabila dilakukan simulasi pada peluang pasar USA seperti pada Gambar 7, dalam arti jika ingin meningkatkan market share perikanan tuna Indonesia di pasar USA, maka komoditas yang dominan adalah canned tuna dengan probabilitasnya sebesar $63 \%$ dimana daerah ekspor utama adalah Surabaya dengan probabilitas sebesar $45 \%$ dan daerah asal adalah Bali dengan probabilitas mencapai $27 \%$ dengan armada yang digunakan armada 10 GT sebesar $31 \%$ dan alat tangkap yang digunakan yaitu handline dengan probabilitas sebesar $29 \%$.
Berdasarkan hasil wawancara, ternyata aspek sosial ekonomi yang paling berpengaruh dalam penentuan ekspor tuna di pasar USA adalah preferensi konsumen di USA yaitu sebesar 19\%, permintaan tuna di USA memang relatif tinggi terutama untuk produk Frozen Tuna baik dalam bentuk tuna saku,loin maupun tuna cube dan steak. Selain itu hasil wawancara menunjukkan bahwa untuk pasar USA biasanya lebih menyukai ikan kaleng dengan lebih banyak brain (garam) dan tanpa minyak, hal ini menjadi pertimbangan bagi pelaku usaha yang ingin memasarkan produknya ke USA. Aspek sosial ekonomi yang berpengaruh lainya adalah hambatan tariff dan hambatan non tariff sebesar masing-masing sebesar $18 \%$. Standar dari FDA yang cukup ketat dalam penentuan produk makanan yang diekspor ke USA menyebabkan hambatan non tariff.

Apabila dilakukan simulasi peluang pasar UE seperti pada Gambar 8, dalam arti jika ingin meningkatkan market share perikanan tuna Indonesia di pasar UE, maka komoditas yang dominan adalah canned tuna dengan probabilitasnya sebesar $78 \%$ dimana daerah ekspor utama adalah Surabaya dengan probabilitas sebesar $50 \%$ dan daerah asal adalah Bali dengan probabilitas mencapai $28 \%$ dengan armada yang digunakan armada 10 GT sebesar $32 \%$ dan alat tangkap yang digunakan yaitu handline dengan probabilitas sebesar $28 \%$.

\section{Pasar USA}

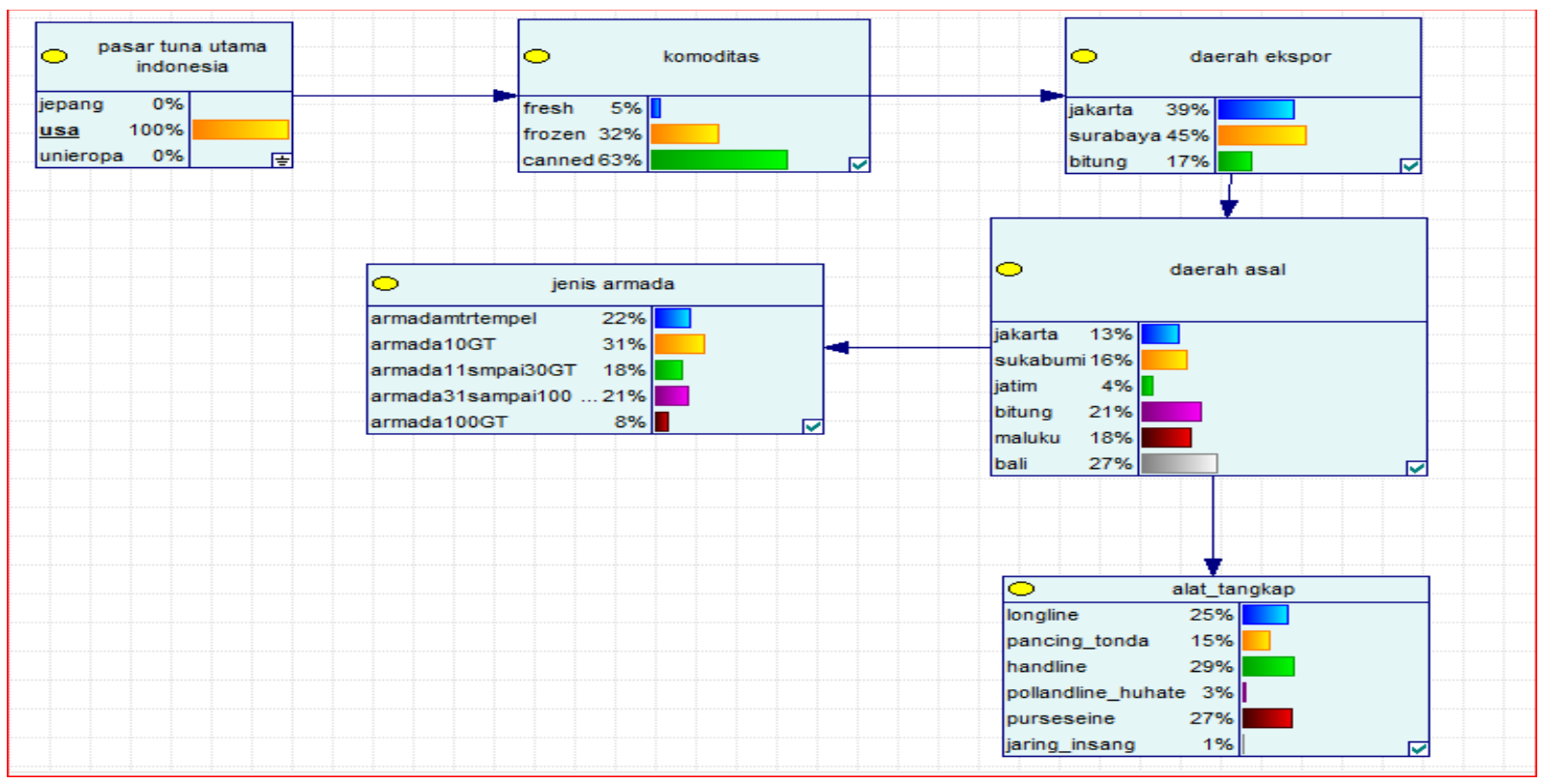

Gambar 7. Data Hasil Olahan untuk Pasar USA (2014). Figure 7. Processed Data for USA (2014). 


\section{Pasar Eropa}

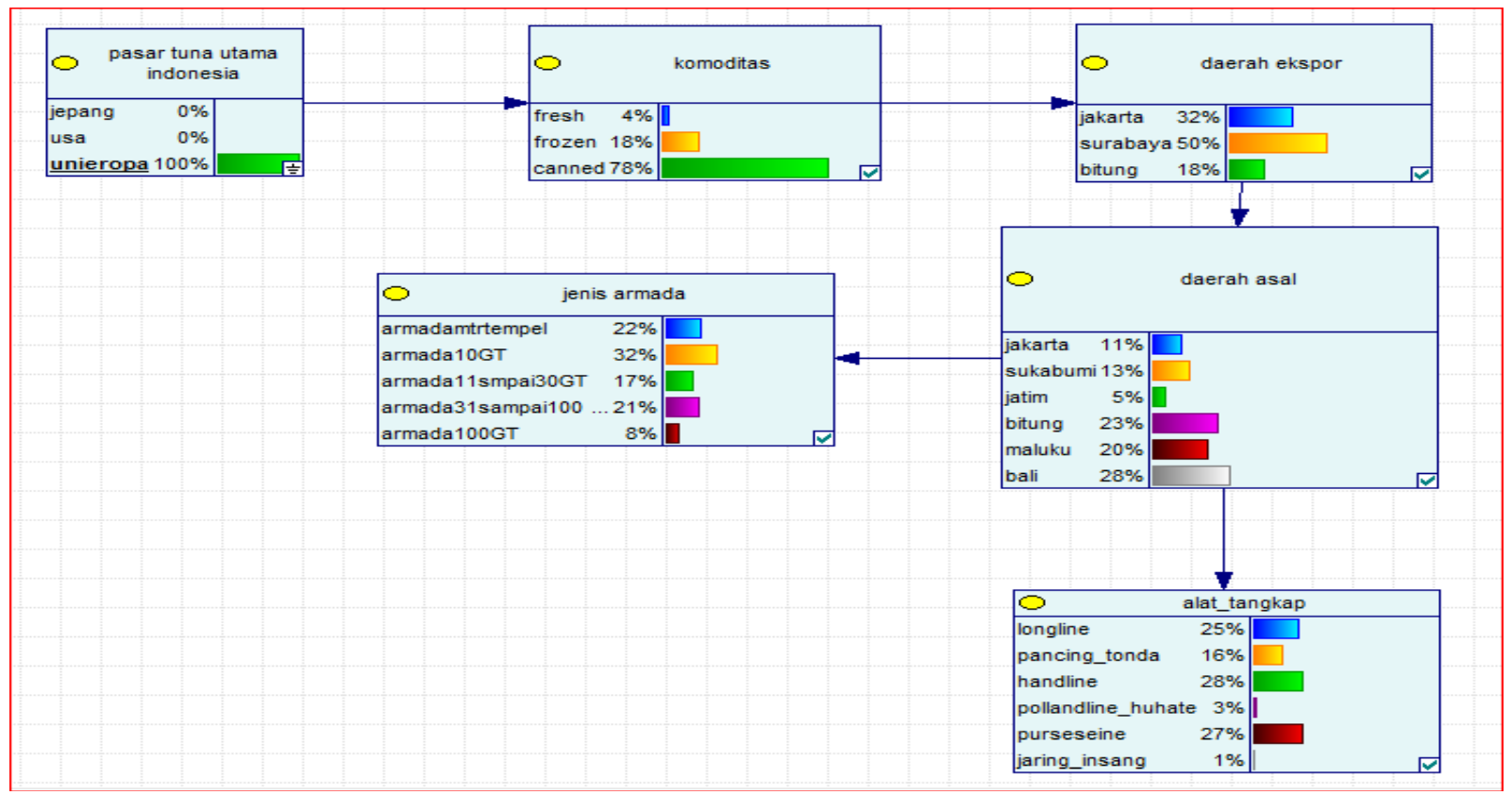

Gambar 8. Data Hasil Olahan untuk Pasar Eropa(2014).

Figure 6. Processed Data for Europe Market (2014).

Aspek sosial ekonomi yang paling berpengaruh dalam penentuan ekspor tuna di UE adalah Hambatan non tariff yaitu biasanya berupa kebijakan Pemerintah Uni Eropa terkait dengan produk Tuna Indonesia yaitu sebesar $22 \%$. Hambatan tarif menjadi pertimbangan tersendiri, berdasarkan data P2HP,KKP tahun 20010-2012 yang telah diolah dapat diketahui bahwa untuk negara di Uni Eropa yang menjadi tujuan utama ekspor dari Indonesia adalah ke negara Jerman sebesar $32 \%$ dari total ekspor tuna dari Indonesia ke Uni Eropa, kemudian Spanyol 21\%, United Kingdom 20\%, dan sisanya adalah berbagai negara lainya.

\section{KESIMPULAN DAN IMPLIKASI KEBIJAKAN}

\section{Kesimpulan}

Berdasarkan hasil yang diperoleh menunjukkan bahwa perikanan tuna Indonesia yang memiliki tiga pasar utama yaitu Pasar Jepang, pasar USA dan pasar UE, dengan probabilitas yang dimiliki pada tiga pasar tersebut yaitu pasar Jepang sebesar 54\%, diikuti pasar USA 24\% dan pasar UE 23\%. Ekspor tuna Indonesia pada ketiga pasar utama tersebut dengan jenis komoditas yang dominan diperdagangkan adalah Canned Tuna dengan probabilitas sebesar 54\%, dan daerah ekspor tuna Indonesia dimana daerah ekspor yang memiliki probabilitas tertinggi berasal dari
Jakarta yaitu sebesar 49\%, sedangkan daerah asal utama adalah daerah terbanyak tiga besar adalah Bali dengan tingkat probabilitas sebesar $26 \%$, Sukabumi sebesar $21 \%$, Bitung sebesar $19 \%$, dan level armada penangkapan untuk tuna adalah armada $\leq 10$ GT $(30 \%)$, armada motor tempel (22\%), armada 31-100 GT (18\%), Terakhir, pada jenis alat tangkap tuna yang digunakan, hasil analiis menunjukkan bahwa alat tangkap yang dominan adalah handline $(31 \%)$, purse seine (28\%), kemudian diikuti long line (26\%).

Selanjutnya, apabila dilakukan simulasi pada pasar Jepang untuk meningkatkan ekspor perikanan tuna Indonesia di pasar Jepang, maka komoditas yang dominan adalah Fresh tuna dengan probabilitasnya sebesar $45 \%$ dimana daerah ekspor utama adalah Jakarta dengan probabilitas sebesar $62 \%$ dan daerah asal adalah Bali dengan probabilitas mencapai $25 \%$ dengan armada yang digunakan armada 10 GT sebesar $28 \%$ dan alat tangkap yang digunakan yaitu handline dengan probabilitas sebesar 33\%. Pada pasar USA, dimana apabila ingin meningkatkan ekspor perikanan tuna Indonesia di pasar USA, maka komoditas yang dominan adalah Canned tuna dengan probabilitasnya sebesar $63 \%$ dimana daerah ekspor utama adalah Surabaya dengan probabilitas sebesar $45 \%$ dan daerah asal adalah Bali dengan probabilitas mencapai $27 \%$ dengan armada yang digunakan armada 10 GT sebesar $31 \%$ dan alat 
tangkap yang digunakan yaitu handline dengan probabilitas sebesar $29 \%$. Terakhir, apabila ingin meningkatkan ekspor perikanan tuna Indonesia pada pasar UE, maka komoditas yang dominan adalah Canned tuna dengan probabilitasnya sebesar $78 \%$ dimana daerah ekspor utama adalah Surabaya dengan probabilitas sebesar $50 \%$ dan daerah asal adalah Bali dengan probabilitas mencapai $28 \%$ dengan armada yang digunakan armada 10 GT sebesar $32 \%$ dan alat tangkap yang digunakan yaitu handline dengan probabilitas sebesar $28 \%$.

\section{Implikasi Kebijakan}

Ekspor perikanan tuna Indonesia pada negara-negara yang merupakan pasar tujuan utama mengalami peningkatan. Peningkatan tersebut dilihat dari market share perikanan tuna Indonesia pada masing-masing negara yang menjadi pasar tujuan utama tuna Indonesia. Oleh karena itu, untuk meningkatkan peluang pasar perikanan tuna Indonesia, diperlukan suatu strategi pemasaran yang tepat agar pangsa pasar (market share) perikanan tuna Indonesia terus meningkat. Salah satu upaya tersebut adalah dengan melakukan aspek penelusuran bahan baku tuna dengan memperhatikan daerah baik daerah yang mengekspor maupun daerah asal ikan tersebut ditangkap dan jumlah armada serta alat tangkap yang digunakan dalam proses penangkapan tuna Indonesia. Selain itu peran pemerintah sangat diperlukan dalam membuat peraturan mengenai traceability agar jaminan mutu dan keamanan pangan produk perikanan tuna terkendali, disamping peran swasta dalam menjamin kualitas ikan mulai dari proses penangkapan sampai proses pengolahan melalui penanganan hasil tangkapan ikan yang baik, sehingga diharapkan dengan upaya-upaya ini diharapkan dapat mendorong peningkatan ekspor komoditas tuna pada ketiga negara tujuan utama.

\section{UCAPAN TERIMA KASIH}

Ucapan terima kasih kepada rekan-rekan peneliti yang terlibat dalam penelitian Kajian Aspek Sosial Ekonomi Perikanan Tuna Dan Strategi Penetrasi Pasar Ekspor Dan Domestik

\section{DAFTAR PUSTAKA}

Comtrade. 2014. Data Base Ekspor Tuna Indonesia Terhadap Ekspor Tuna Dunia PadaTahun 2001-2013. UN Comtrade.
Direktorat Jenderal Pengolahan dan Pemasaran Hasil Perikanan (Ditjen P2HP). 2014. Statistik Ekspor Hasil Perikanan Indonesia, Kementerian Kelautan dan Perikanan. Jakarta.

Dinas Kelautan dan Perikanan (DKP) Provinsi Bali. 2013. Statistik Perikanan Tangkap. Dinas Kelautan dan Perikanan Provinsi Bali.

Dwiyitno. 2009. Implementasi Sistem Ketertelusuran Pada Produk Perikanan. Squalen. Vol. 4 no. 3 Desember 2009.

Food and Agricultural Organization (FAO). 2011. OECD-FAO Agricultural Outlook 2011-2020.

FishStat Data. 2011. Global Fish Commodity Production and Trade. Food and Agriculture Organization of The United Nations.

Jeynes, E. T. 1995. Probability Theory: The Logic of Science. Washington University, USA.

Koestranti, R. 1993. kajian Impor Pasar Jepang Terhadap Tuna (Thunnus sp) Indonesia. Program Studi: Sosial Ekonomi Perikanan Fakultas Perikanan Institut Pertanian Bogor. Bogor.

Lestari, W. 2012. Analisis Dan Strategi Peningkatan Daya Saing Tuna Olahan Indonesia Di Pasar Internasional. Magister Profesional/Program Studi Industri Kecil Menengah. Sekolah Pascasarjana. Institut Pertanian Bogor. Bogor

Lestari, W., R. Syarief dan K. Sumantadinata. 2013. Strategi Peningkatan Daya Saing Tuna Olahan Indonesia di Pasar Internasional. Manajemen IKM, Februari 2013 (36-44) Vol. 8 No. 1 ISSN 2085-8418.http://journal.ipb.id/index.php/ jurnalmpi

Liu, J.J. and S.G. Shang. 2012. Application of the Bayesian Decision-Making. DOI:10.7763/IPEDR: 50-54.

Miyake, M., P. Guillotreau, C-H. Sun, and G. Ishimura. 2010. Recent developments in the tuna industry: stocks, fisheries, management, processing, trade and markets. FAO Fisheries and Aquaculture Technical Paper. No. 543. Rome, FAO. 2010. $125 p$.

Nikijuluw, V. 2014. Penggunaan Model Peluang Bayesian Untuk Analisis Forensik Pemasaran: Konsep Teoritis dan Aplikasi Data Hipotetik. Jakarta.

Preatin, K. Yahya dan Yos Rusdiansyah. 2007. Analisis Survival Dengan Pendekatan Bayesian Untuk Memodelkan Ketahanan Program KB Pada Individu lbu di Indonesia Tahun 2007. http://digilib.its.ac.id/public/ITSMaster-88611308201035-Paper.pdf 
Rossi, P. E. 2002. Bayesian in Statistic and Marketing. Fisher College of Business Ohio State University. Ohio.

Sunoto. 2010. Rantai Nilai Value Chain Peningkatan Produksi Perikanan dengan Konsep Minapolitan. Bahan Presentasi (tidak dipublikasikan).

Syamsudin, M. 2011. Teorema Bayes. Industrial and Financial Mathematics FMIPA ITB \& Financial Modeling, Optimization and Simulation (FinanMOS) ITB. Bandung

Winanti, A. 2011. Analisis Permintaan Ekspor Ikan Tuna Segar Indonesia di Pasar Internasional. Sekolah Pascasarjana Institut Pertanian Bogor. Bogor. 